chapters one frequently encounters novel items of information and 'know-how' not previously seen in publications of this kind.

The bibliography quoted is extensive but, perhaps inevitably, predominantly American. During the Second World War, and particularly in its early stages, the Americans were supplied with a great deal of information from Great Britain about the design and manufacture of small solid-propellant rocket motors. It is always a little disappointing that British workers who have played a conspicuous part in these developments are not as well known as they deserve to be, mainly because they have been associated with material which only slowly finds its way into the 'open' literature.

While the book is very readable and informative, there are some omissions. For example, in the section dealing with composite propellants there is no mention of 'plastic propellant', a wholly British concept which started during the War. This propellant has a good performance and possesses exceptional chemical stability. Its main ingredients are ammonium perchlorate (the oxidant) and a hydrocarbon binder (the fuel) ; these are mixed together to form. a stiff 'putty' which can then be pressed into the desired shape in a rocket tube. Plastic propellant is used in a range of fairly large motors, notably in the Skylark rocket, which has been employed in the upper atmosphere research firings in Australia.

In the discussion on "Ballistic Agents", minor ingredients used to modify the burning characteristics of propellants, it is mentioned that potassium sulphate was originally used to reduce the flash and smoke in guns. This latter point, that is to say, smoke reduction, is incorrect, since any inorganic additive must aggravate the smoke problem. However, the book is well edited and no slips of real significance have been noted.

The final chapter deals with "The Future of Propellants". This outlines very clearly the possibility of developing propulsion systems of greatly enhanced performance by various applications of nuclear power.

The author is to be commended on producing a very readable book which contains a useful blend of basic information and technology. It can be recommended to those seeking a good introduction to all aspects of rocket propellants.

W. B. LitTLER

\section{AN EASY GUIDE TO RADIO ASTRONOMY}

Radio Studies of the Universe

By Dr. R. D. Davies and Dr. H. P. Palmer. Pp. viii $+200+14$ plates. (London: Routledge and Kegan Paul, Ltd., 1959.) 25s. net.

$\triangle \mathrm{S}$ the joint authors of this book are two experienced radio astronomers working at the Jodrell Bank Experimental Station, the authoritative nature of the material is assured. The book is intended for the non-specialist, and does not assume any appreciable previous knowledge of either radio or astronomy. It can be recommended as a useful and informative outline of the results achieved in all aspects of this progressive new branch of scientific activity.

The book begins with a brief outline of optical astronomy; then a description of radio methods is followed by an account of the various sources of radio emission beyond and within the Galaxy including the Sun and solar system. Subsequent chapters deal with the application of radar to the study of meteors, auroræ, the Moon and planets, and the contribution of radio-astronomical methods to the study of the Earth's upper atmosphere. There are a useful glossary and a selected list of references. The book is printed in large type and illustrated with plates and diagrams.

The writing of books of this class, often described as 'semi-popular', presents the problem of conveying a correct meaning without encumbering the reader with the detailed concepts of rigorous treatment. In this elementary survey of radio astronomy, the authors have for the most part succeeded well in this respect. In some places a slight amplification would have been helpful. It would have been worth attempting to show, possibly in a further appendix, how the expressions for the beam-width of a radio telescope and for the lobes of an interferometer pattern are derived, as these involve only elementary ideas of wave motion. The significance of band-width in radio noise reception could also have been more adequately covered.

Only in a few instances could one feel more particularly critical of the authors' approach. For example, a statement that the amount of radiation received by an aerial is proportional to its area is followed by a discussion of linear aerials, and it is not made clear what 'areas' they possess. Later, radar echoing properties of objects are again loosely identified with their 'areas'. A different type of misleading impression arising from inadequate explanation occurs, for example, in the description of visual solar activity, where a statement ". . . when the outer edge of the Sun is viewed through a telescope..." neither suggests the necessary precautions nor the special technique involved in making optical solar observations. It would not, however, do justice to the book to dwell unduly on a few defects of detail. The book as a whole provides a simple and comprehensive guide to radio astronomy.

J. S. HEY

\section{PROBLEMS OF SPACE FLIGHT}

\section{Vistas in Astronautics}

Vol. 2. Edited by Morton Alperin and Hollingsworth F. Gregory. Second Annual Astronautics Symposium sponsored by Air Foree Office of Scientific Research, and Institute of Aeronautical Sciences. (International Series of Monographs on Aeronautical Sciences and Space Flight. Division 7: Astronautics, Vol. 2.) Pp. $x+318$. (London and New York: Pergamon Press, 1959.) 105s. net.

Trist THE second Astronautics Symposium organized by the U.S. Air Force Office of Scientific Research was held at Denver Colorado, in April 1958, and this volume records the proceedings. The papers can conveniently be divided into four groups. The first group is concerned mainly with scientific experiments in space, and includes a concise survey by S. F. Singer of the outstanding scientific problems in the region out to the Moon's distance. The second and largest group deals with the propulsion, orbits, control and guidance of space vehicles. There is a significant paper by A. Ferri and others, who conclude that the use of turbo-jet and ram-jet engines in the launching 